\title{
A Case Report on Osborn Waves of Hypothermia Induced LV Systolic Dysfunction
}

\author{
Dr.Rajnandini Singha ${ }^{1 *}$, Dr. Amazing Grace Siangshai ${ }^{1}$, Dr.Jashlyn Lijo ${ }^{2}$ \\ ${ }^{1}$ PharmD intern, Nandha College of Pharmacy, Pitchampalayam, Erode, Tamil Nadu, India. \\ ${ }^{3}$ Clinical pharmacist, Apollo Speciality Hospitals, Madurai, Tamil Nadu, India. \\ *Corresponding author's E-mail: rajnandinisingha25@gmail.com
}

Received: 22-06-2021; Revised: 15-09-2021; Accepted: 24-09-2021; Published on: 15-10-2021.

\section{ABSTRACT}

Hypothermia, described as a core body temperature of $<95 \%$, is associated with ECG alteration abnormalities. Sinus bradycardia occurs when the body temperature drops below $90^{\circ} \mathrm{F}$, and is correlated with gradual prolongation of the PR interval, QRS complex, QT interval. It can progress to ventricular and atrial fibrillation at a temperature reaching $89^{\circ} \mathrm{F}$, which can lead to left ventricular dysfunction. Hypothermia is connected to the osborn waves, which at the end of the QRS complex consist of additional deflection. The inferior and lateral precordial leads are seen by Osborn waves, also known as J waves, Camel hump waves and hypothermic waves. As the body temperature decreases, it becomes more pronounced and a gradual expansion of the QRS complex raises the likelihood of ventricular fibrillation causing ventricle dysfunction.

Keywords: Hypothermia, Left ventricular systolic dysfunction, Osborn waves, Heart rate, prolonged ejection time, Left ventricular ejection fraction.

QUICK RESPONSE CODE $\rightarrow$

DOI:

10.47583/ijpsrr.2021.v70i02.004

DOI link: $\underline{\text { http://dx.doi.org/10.47583/ijpsrr.2021.v70i02.004 }}$

\section{INTRODUCTION}

ypothermia is a core body temperature below $35^{\circ} \mathrm{C}$ $\left(95^{\circ} \mathrm{F}\right)$ that causes cardiac tissue generalized slowing of impulse condition, seen in ECG and electrocardiogram as prolongation of ejection time, widening of QT intervals, RR, PR and QRS ${ }^{1}$. As part of the stress response, sinus tachycardia occurs in the early phases of hypothermia. Sinus bradycardia, combined with gradual prolongation of the PR interval, QRS complex, and QT interval, survives when the temperature drops below $90^{\circ} \mathrm{F}^{2}$.

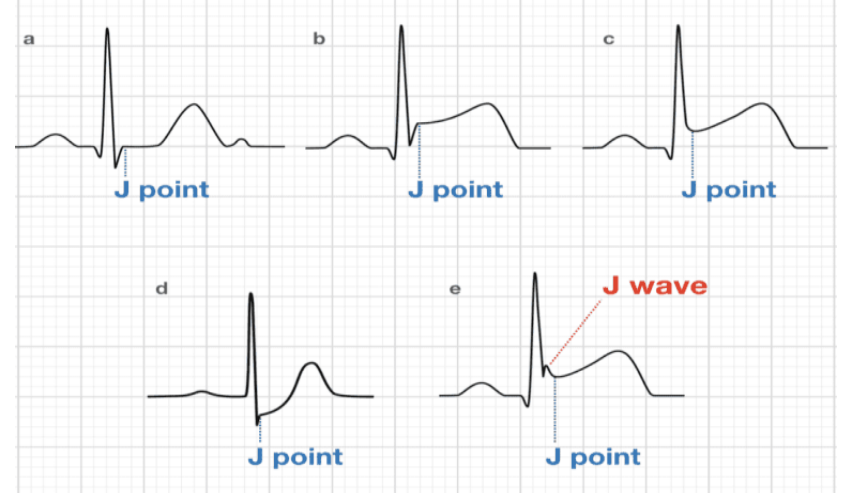

Figure 1: ECG abnormalities associated with (J Waves)

\section{Hypothermia Induced ECG Abnormalities (J Waves)}

The J waves (figure 2) finding of hypothermia include:

1. The "Osborne wave" in the QRS complex is characterized by a label in the downward part of the $R$ wave and is associated with hypothermia, hypocalcaemia and Brugada syndrome.

2. Due to obesity, chronic obstructive pulmonary disease or COPD, pericardial effusion, low voltage on the ECG may occur.

3. Osborn waves are responsible for sinus bradycardia, junctional bradycardia, atrial fibrillation with sluggish ventricular response or higher-grade AV blocks.

4. Baseline hypothermia signs are shivering and shivering.

Osborn wave hypothermia has been reported to decrease systolic and diastolic left ventricular function ${ }^{3,4}$. This case involved a patient with hypothermia with reduced heart rate, pulse rate, respiratory rate, elevated systolic pressure, and prolonged progression of the ejection period to left ventricular systolic dysfunction with low ejection fraction ${ }^{5}$.

\section{CASE PRESENTATION}

A 70year old female patient was presented in the hospital in unconscious state with a body temperature lower than $33^{\circ} \mathrm{F}\left(90^{\circ} \mathrm{F}\right)$. Patient had history of Type 2 Diabetes Mellitus for 10 years and Old Cerebrovascular Accident. The current symptoms were fatigue, weakness, dizziness, swelling of legs. The past medications were T. Aspirin75mg and T. Metformin 500mg. The Physical examinations showed blood pressure of $140 / 89 \mathrm{mmhg}$, heart rate of 45 beats per minutes, Respiratory rate of 10 beats per minutes and oxygen saturation $\left(\mathrm{SpO}_{2}\right)$ of $96 \%$ on nasal oxygen supply. 
On systemic examination bilateral crepts were heard. Warmed saline and inotropic support was administered, Also the patient's temperature normalized over three hours.

The electrocardiogram showed bradycardia, sinus arrest, osborn waves were apparent on lead V4 to V6, electrocardiography showed left ventricular dysfunction, left ventricular ejection fraction of $28 \%$ and prolonged ejection time of 0.75 seconds, USG abdomen /pelvis showed hepatomegaly and a X-Ray showed lung congestion and pleural effusion.
Laboratory parameters showed increase WBC $\left(12 \times 10^{9} / \mathrm{L}\right)$, ESR (70mmhr), RBS (169mg/dl), SGOT (40IU/L), SGPT $(47 \mathrm{IU} / \mathrm{L})$ and decrease in levels of $\mathrm{HB}(10 \mathrm{~g} / \mathrm{dl})$ and serum creatinine $(0.3 \mathrm{mg} / \mathrm{dl})$. Patient's final diagnosis showed hypothermia induced left ventricular dysfunction, Old Cerebrovscular Accident and Type 2 Diabetes Mellitus. On the sixth day, ejection time reduced, normal systolic pressure and left ventricular ejection fraction was $43 \%$ then followed by $48 \%$.

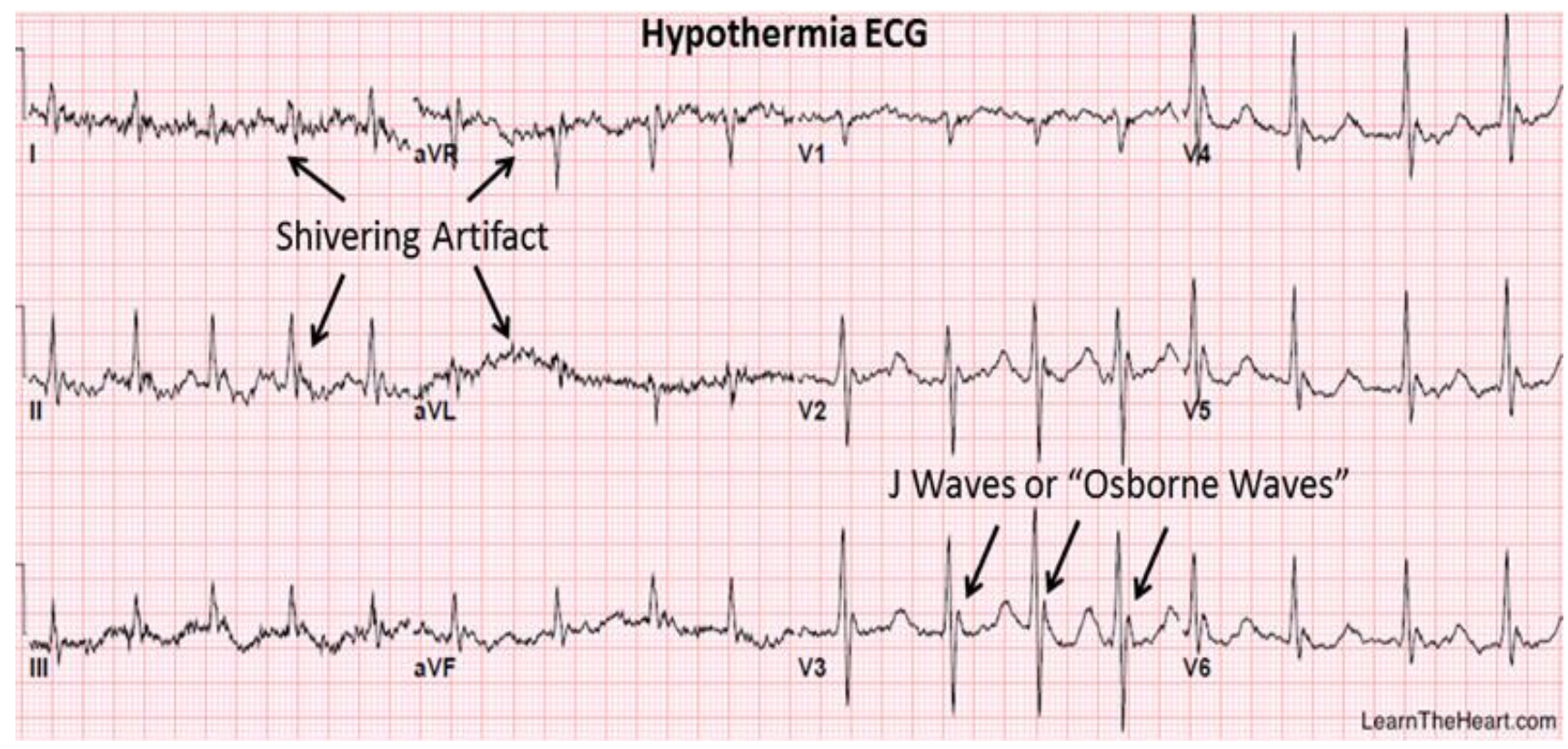

Figure 2: Hypothermia Induced ECG abnormalities (J Waves)

\section{DISCUSSION}

Hypothermia induced ECG abnormalities shows a prolongation in the $\mathrm{PR}, \mathrm{RR}, \mathrm{QRS}$, and QT intervals and as a result ventricular fibrillations occurs, which leads to left ventricular dysfunction ${ }^{1}$. Hypothermia cause reduced left ventricles contractile indexes, suggest left ventricular systolic dysfunction ${ }^{2}$. Its pathophysiology seems to involve intracellular $\mathrm{Ca}^{2+}$ overload that may partly attributed to hypothermia-induced inhibition of the $\mathrm{Na}^{+} / \mathrm{K}^{+}$-ATPase in the sarcolemma, partly impaired the clearance of free cytosolic $\mathrm{Ca}^{2+}$. Hypothermia is a temperature-dependent dysfunction of ion transport mechanisms, where dysfunction of ion transport mechanisms due to lack of ATP and with production of reactive oxygen species, causes $\mathrm{Ca}^{2+}$ overload and modification of contractile proteins $^{3,4}$.

A decrease in pulse and cardiac output and may increase atrial or ventricular arrhythmias and osborn waves ${ }^{5}$. A decrease heart rate and a prolonged ejection time is a hemodynamic parameter used to compute stroke volume and is inversely proportional to heart rate. Patients with heart failure and acute myocardial infarction showed significant decrease in ejection time ${ }^{6}$. In this case, the ejection time was clearly prolonged ( 0.75 seconds), which is a major characteristic finding of hypothermia-induced left ventricular systolic dysfunction. Lung congestion and pleural effusions are considered to be due to left ventricular dysfunction ${ }^{7}$.

Low levels of creatinine implicate hepatic dysfunction and passive hepatic congestion is due to increased central venous pressure may cause elevation of liver enzymes and both direct and indirect serum bilirubin which may be a reason of hepatomegally in this case ${ }^{8}$. Impaired perfusion from decreased cardiac output may be associated with acute hepatocellular necrosis with marked elevation in serum aminotransferases. So, it can be concluded that hepatomegally is due to left ventricular dysfunction ${ }^{9}$.

\section{CONCLUSION}

We concluded that our patient had experienced a coma and heart failure due to accidental hypothermia. Hypothermia can impair left ventricular contraction and may specifically result in prolongation of the ejection time and reduced heart rate. These findings may be a characteristic finding of hypothermia-induced cardiac dysfunction 


\section{CONSENT}

Written informed consent was obtained from the patient for publication of this case report.

\section{REFERENCES}

1. Paurush Ambesh MD, et al. Osborn waves of hypothermia: Cleveland Clinic Journal of Medicine. 2017 October; 84(10):746-747.

2. Imad A. Alhaddad, et al. Osborn Waves of Hypothermia: Department of medicine, Bronx Lebanon hospital centre, Bronx,NY. 27 June 2000; 101:e233-e244.

3. Rituparna S, et al. Occurrence of "J Waves" in 12-Lead ECG as a Marker of Acute Ischemia and Their Cellular Basis. Pacing Clin Electrophysiol. 2007 Jun,30(6):817-819.

4. Filseth $\mathrm{OM}$, et al. Post-hypothermic cardiac left ventricular systolic dysfunction after rewarming in an intact pig model. Crit Care. 2010.
5. Nordmark J, et al. Assessment of intravascular volume by transthoracic echocardiography during therapeutic hypothermia and rewarming in cardiac arrest survivors. Resuscitation. 2009; PMID: 19716641.

6. Siniorakis $E$, et al. Myocardial damage after prolonged accidental hypothermia: a case report. J Med Case Rep. 2009; 3: 8459.

7. Takanao Mine, et al. Left ventricular systolic dysfunction in a patient with accidental hypothermia: a case report, 2018;6: 429.

8. Lance VQ, et al. Heart rate-left ventricular ejection time relations. Variations during postural change and cardiovascular challenges. Br Heart J. 1976; 38(12): 13321338.

9. Alvarez AM, et al Liver abnormalities in cardiac diseases and heart failure.2011;20(3): 135-142.

Source of Support: The author(s) received no financial support for the research, authorship, and/or publication of this article.

Conflict of Interest: The author(s) declared no potential conflicts of interest with respect to the research, authorship, and/or publication of this article.

For any question relates to this article, please reach us at: editor@globalresearchonline.net New manuscripts for publication can be submitted at: submit@globalresearchonline.net and submit_ijpsrr@rediffmail.com 